\title{
El eco de otra Alina. Intertextualidades en «Lejana», de Julio Cortázar
}

\section{Vilma Arrieta Vargas}

Universidad Nacional de Costa Rica

El análisis del conocido cuento de Cortázar demuestra la existencia de vínculos intertextuales, algunos evidentes y otros ocultos entre los meandros del lenguaje. Alina, la protagonista, utiliza esta técnica como parte del juego de identidades y alude a diversas obras relacionadas entre sí por la misma temática del desdoblamiento de identidades, en diferentes niveles de referencia que van desde la duplicación en el espejo hasta niveles más profundos de la conciencia.

El retrato de Dorian Gray' menciona al inicio del Diario «Oh, esa cara de foca balbuceante, de retrato de Dorian Gray a lo último» (90) ${ }^{1}$. Se refiere a la novela escrita por el poeta Oscar Wilde en 1891, en la cual, como se sabe, Dorian conserva su extremada belleza física gracias al envejecimiento experimentado por el retrato que le obsequia su amigo Basile. La duplicación se realiza a través de esa pintura que representa el alma del joven y expresa el lado oscuro y maligno de la personalidad.

Entre los textos que Alina repite para conciliar el sueño están los versos: «Tengo que repetir versos» (90). También recuerda una plegaria en inglés: «Now I lay me down to sleep» (90), cuyo significado, sin embargo, no alude a la realidad de Alina puesto que el

1. «Lejana». en Be’stiaric) (1951). En adelante se citará la siguiente edición: Julio Cortázar. Los relatos. Pasaje's (Madrid: Alianza Editorial. 1976) 88-98. 
insomnio es uno de sus primeros síntomas de inconformidad con su propia vida cotidiana. Pero el sentido repetitivo de la oración, Alina pretende entrar en una especie de sueño creado lingüísticamente, mediante la repetición de términos para crear nuevas realidades. En esta plegaria se hace una relación directa entre el estado de la muerte y el sueño, por lo cual se le pide a Dios que guarde el alma mientras duerme. En conclusión, el sueño se interpreta como un estado semejante a la muerte:

\section{Now I lay me down to sleep \\ I pray my Lord my soul to keep \\ If I should die before I wake \\ I pray the Lord my soul to take.}

Jesualdo explica la presencia de los poemas infantiles, así como la necesidad de repetir palabras o sílabas armoniosas o secretas, principalmente a la hora del sueño, como parte de la necesidad del ser humano de evadir la realidad por medio del mito, la magia y los juegos del lenguaje ${ }^{2}$. En esto consiste la necesidad de Alina, quien evade su cotidianeidad, mientras crea a su doble en horas de vigilia y soledad.

Otros versos que emplea Alina para conciliar el sueño reproducen con algunas variantes parte del «Romance de la luna, luna» de Federico García Lorca: «La luna bajó a la fragua con su polisón de nardos, el niño la mira mira, el niño la está mirando» $(90-91)^{3}$.

De nuevo se conciben el sueño y la muerte como estados paralelos, con la imagen de un niño muerto, cuyos ojos abiertos reflejan la luna, símbolo ella también de la muerte porque es de fría plata. Además, el agua posee el simbolismo del nacimiento, que se invierte porque se refiere a la muerte. Por su parte, la luna se duplica en el retlejo del agua, al igual que la muerte se dobla en la mirada del

2. Jesualdo, La literatura infantıl (Buenos Aures: Losada. 1963) 228-230.

3. En el poema de Lorca: «El niño vino a la fragua con su polisón de nardos. El niño la mira. mira. El niño la está mirando». 
niño. La muerte, límite entre la conciencia y la inconsciencia, permite percibir la vigilia como un doble del sueño, estados que se oponen y complementan en el cuento de Cortázar.

El otro poema al que Alina hace alusión es «Clair de Lune» de Paul Verlaine: «Votre âme est un paysage choisi...» (92). Lo menciona cuando toca el piano y desea expresar sus sentimientos más allá de las palabras que forman la vida cotidiana, mientras Nora toca Fauré, es decir, la musicalización del poema:

\section{Votre âme est un paysage choisi}

que vont charmamt masques et bergamasques,

jouant du luth el dansant et quasi

tristes sous leurs déguisements fantasques.

Tout en chantant sur le mode mineur

l'amour vainqueur et la vie opportune,

ils n'ont pas l'air de croire à leur bonheur

et leur chanson se mêle au clair de lune,

au calme clair de lune triste et beau,

qui fait rêver les oiseaux dans les arbres

et sangloter d'extase les jets d'eau

les grands jets d'eau sveltes parmi les marbres.

Según se ha mencionado, en poemas como este, «la media luz es más rica en fuerza sugestiva y más estimulante para la imaginación que la plena luz del sol, y (que) las palabras que «implican» emoción tienen más poder comunicativo que las palabras que designan la emoción misma» ${ }^{4}$. Para Verlaine los sentimientos se expresan como música y símbolos universales. En «Clair de Lune» el alma es un lugar escogido, especial; más allá de lo visible hay una presencia oscura, etérea y

4. Anna Balakian. El morimiento simbolista (1967) (Madrid: Guadarrama, 1969) 83. 
para encontrarla el yo real debe sufrir un cambio. En ocasiones este poema ha sido relacionado con el ensueño, la fascinación de Diana que indica el aniquilamiento temporal ${ }^{5}$.

En estos textos recordados por Alina, la sensación de irrealidad, la alusión a la muerte, el paisaje lunar, todo convoca la nocturnidad, el mundo oscuro del que proviene la lejana.

\section{Dos narradoras de cuentos}

Junto a estas menciones, el lector avisado descubre una curiosa relación entre «Lejana» y «La historia de Alí-Sar y la esclava Zumurrud», de Las mil y una noches ${ }^{6}$. En esta historia se menciona al otro como el lejano, el innombrable que sólo puede percibirse por medio de la lectura codificada, como los anagramas, palíndromos y la cábala, como sucede con «esa que es Alina Reyes pero no la reina del anagrama» (91). En el cuento oriental, Zumurrud, la protagonista se vale de la geomancia o adivinación por medio de líneas y puntos trazados en la tierra o en una tabla, con la finalidad de esconder el verdadero yo: «Con la geomancia has visto la verdad: en realidad el lejano es un cristiano» ${ }^{7}$. El término lejano es aclarado por el traductor porque «el narrador musulmán no quiere pronunciar, ni siquiera por boca de otro, las palabras 'soy un cristiano'». El lejano es «yo» 8 .

De igual manera en el cuento de Cortázar, la Lejana y el yo son lo mismo, pero solamente se identifican gracias a la lectura codificada. Asimismo, Alina es una especie de Scherezada, personaje central de Las mil y una noches. Las dos son narradoras de cuentos: como Scherezada, cada noche Alina crea una historia en torno a la existencia

5. Jaime Giordano. La edad del ensueño (Santiago de Chile: Editorial Universitaria. 1970) 100.

o. Alí. amante de Zumurrud. se deja arrebatar a la joven por un cristiano y su hermano. El cristiano, que simula ser musulmán. la esclaviza. Raptada luego por un ladrón, huye, se disfraza de hombre y se convierte en rey. En esta posición. para vengarse de sus ultrajadores finge conocer la geomancia. Finalmente. los amantes se reencuentran. Las mil y una noches (traducido por Maria Pia della Rocca. Barcelona: Sopena, 1975) 31-50.

7. Las mil y una noches. 45.

8. Nota de Maria Pia della Roca. Las mil y una noc/hes. 45. 
de Lejana y la escribe en su Diario. Ambas como narradoras, se reservan el derecho de contar el final otro día o en otra oportunidad. Alina nos advierte en su Diario: «No escribiré el final de lo que había pensado» (96), y Scherezada, por su parte, al llegar el día suspende la narración: «se dio cuenta de que amanecía y, discreta, se calló» ${ }^{9}$.

La esclava Zumurrud es narradora de cuentos, como Alina es repetidora de versos:

Mis lágrimas son una auténtica historia, con desvanecimientos y abandonos, trasmitida por una larga cadena de narradores ${ }^{10}$.

Con grandes muestras de asombro recitó estos versos ${ }^{11}$.

No te admires de las maravillosas poesías que conoce de memoria ${ }^{12}$.

Scherezada se desdobla en Zumurrud, quien al mismo tiempo se desdobla para esconder su verdadera identidad: es como si Alina se duplicara en la narradora también desdoblada de otro cuento.

El personaje femenino, Zumurrud, es una esclava que llega a convertirse en rey. Es decir, no sólo se duplica para cambiar de clase social sino que se «convierte» en varón para salvar su vida. En estas alusiones a la duplicación y el desdoblamiento, se menciona la posibilidad de no encontrar la integración o unificación del ser, ya que «el final de toda compañía es la separación» ${ }^{13}$.

En uno de los desdoblamientos que sufre Zumurrud es una mujer a quien por las noches envían a cuidar las cenizas de la cocina, una especie de Cenicienta: «arrastradla por los pies y tiradla a la cocina» ${ }^{14}$,

9. Las mil y una noches, 31

10. Las mil y una nochess, 4

11. Las mil y una nochess. 34.

12. Las mil y una nochess. 36 .

13. Las mil y una noches. 38.

14. Las mil y una nochess. 39. 
situación que puede relacionarse con la expresión de Alina: «aquella que odio de noche» (91).

También el enunciado «el eco de otra Alina», en referencia a Lejana como su otro está incluido en el discurso de Zumurrud: «Ella se paró para interrogar el lugar, que le contestó como un eco: ya es imposible encontrarse» 15 .

Cuando Alí y Zumurrud son obligados a separarse, para lograr el encuentro siguen un laberinto formado fundamentalmente por los mismos elementos simbólicos que se presentan en «Lejana»: el mercado, la plaza, el puente, la ciudad, la boda.

En relación con el puente se dice, por ejemplo: «No volverás a ver a tu amada más que sobre el puente as-Sirát», que según nota del traductor significa "puente afilado y estrecho tendido sobre el infierno, por el cual deben cruzar las almas camino al cielo» ${ }^{16}$.

Y también Alina y Lejana se encuentran en el puente sobre el río Danubio, el cual, en el momento del desdoblamiento, presenta iguales connotaciones: «y del Danubio crece un viento de abajo, difícil, que engancha y hostiga» (97).

Ambos puentes se encuentran en la ciudad. Alí realiza un largo viaje a este lugar, mientras que en el cuento es Alina quien viaja a Budapest para encontrarse con Lejana.

En cuanto a la boda, Zumurrud se vale de Alí y se casa con él para cumplir sus propósitos de liberarse, igual que sucede con Luis María. Sin embargo, Alí sí realiza el amor sexual, de un modo parecido al que señala Nora en el cuento de Cortázar: «no sabe lo que se echa encima. O debajo, como dice Nora» (96). Este juego de palabras de Alina se relaciona con la experiencia sexual de Alí con Zumurrud disfrazada de rey. Alí desconoce la identidad de su seductor y, por lo tanto, no sabe qué actitud tomar:

15. Las mul y una nociness to.

16. Las mil y una noches. 48. 
Bájate los pantalones y tiéndete boca abajo, si no quieres que te corte la cabeza. Obedeció y ella subió sobre sus caderas. La sintió lisa como la seda y pensó para sus adentros: este rey es más delicado que todas las mujeres ${ }^{17}$.

En este caso, el rey es el yo que se convierte en el otro: Zumurrud: así Alina, por medio del matrimonio se transformará en Lejana, su otro yo.

Además de estas cercanías existen otras más escondidas. Por ejemplo, los cuentos de Scherezada están numerados de acuerdo con cada noche. Las siete fechas del Diario de Alina pueden referirse a una numeración de tipo cronológico y están representadas por días y meses, en una simbología, tal vez, cabalística:

noche 121 (12 de enero: 12-1), noche 201 (20 de enero: $20-1$ ), noche 251 (25 de enero: $25-1$ ), noche 281 (28 de enero: $28-1$ ), noche 300 (30 de enero: $30-1$ ), noche 301 (31 de enero: $31-1$ ), noche 72 (7 de febrero: $7-2$ ).

Como puede apreciarse, se sigue un orden numérico lógico de acuerdo con la cronología; la noche 72 nos orienta a creer que la ruptura del orden numérico se debe al momento de la relectura del Diario realizada por Alina: «Era peor, un deseo de ir conocer al ir releyendo» (96) y la enunciación del desdoblamiento: «En el puente la hallaré y nos miraremos» (97).

\section{La Cenicienta}

En el complejo juego de alusiones literarias de «Lejana» se encuentra una mención velada al cuento tradicional «La Cenicienta», recopilado, entre otros, por Basile y Perrault.

i7. Lasmily una nocilies. 50. 
Las historias de «Cenicienta» y «Lejana» están codificadas en forma diferente, pues el texto se duplica asimismo en un juego de oposiciones, en forma externa. De la misma manera se da esa duplicación cuando Alina crea a Lejana en su propio Diario.

Parece que la Cenicienta proviene de la cultura china en los alrededores del siglo IX después de Cristo; es sabido que esta sociedad considera como modelo de belleza el pie pequeño de las mujeres, de aquí la importancia que adquiere el zapato o zapatilla, como elemento para identificar al personaje auténtico. En la mayoría de las versiones, Cenicienta es reconocida gracias al zapato, razones por las cuales, tanto el pie como el zapato «son símbolos de virtud, distinción y belleza» ${ }^{18}$.

El cuento infantil se escribió en 1697, pero su existencia es anterior, pues pertenece a la tradición oral. Según Soriano ${ }^{19}$, La Gatta Cenerentola de Basile fue la inspiración de Perrault. En Basile, la heroína es culpable del delito y sus consecuencias. Por ejemplo, en un momento determinado, degüella a la madrastra al cerrar un baúl en el cual ella había metido su cabeza; en otras versiones es inocente y víctima.

La «Cenicienta» de Perrault es una versión radicalmente diferente a la de Basile. Perrault produjo un texto más pulido, acorde con la época cortesana; por ejemplo, introduce la zapatilla de cristal no sólo por factores estéticos sino para levantar la imagen de la heroína y evitar aspectos desagradables de las historias anteriores, como las mutilaciones. Además, Cenicienta adquiere características sumisas que coinciden con el desempeño de oficios domésticos y de la actitud de las mujeres en la corte. Porotra parte, en la historia de los hermanos Grimm la heroína es más decidida y auténtica, incluso el príncipe la acepta vestida de harapos.

A pesarde las diferencias, todas las historias tienen en su esencia las mismas características: al principio la heroína goza de respeto, pero se degrada repentinamente, ya sea por la muerte de su madre o por la

18. Bruno Bettelheim. Análisis de los cuentos de hadas (1975) (Madrid: Crítica. 1988) 331.

19. Marc Soriano. Los cuentos de Perrault. Erudición y tradiciones populares (Buenos Aires: Siglo XXI, 1968) 146-149. 
boda de su padre. En todo caso, la relación con la madre resulta conflictiva pues, como se sabe, el cuento de hadas desarrolla relaciones de amor-odio entre padres e hijos. Otro elemento común es que Cenicienta es reconocida por la zapatilla. En cuanto a la causa de la degradación, esta difiere en las diversas versiones (incesto, agresión física o culpabilidad de la heroína).

El vocablo Cenicienta está ligado con pureza, virginidad y con tradiciones muy antiguas, en las cuales se utilizaban vírgenes vestales: mujeres jóvenes absolutamente puras dedicadas al sagrado oficio de cuidar el fuego. Parece que desempeñaban esta función de sacerdotisas durante un tiempo determinado y al concluir adquirían el derecho de casarse con hombres de la nobleza. También Cenicienta es una virgen que está al cuidado del fuego y de ahí su nombre. Bettelheim explica que, posiblemente con el advenimiento del cristianismo, este trabajo sagrado se degradó, pues los cultos femeninos fueron sustituidos por un dios padre servido por varones. En este sentido, Cenicienta se puede considerar también como la diosa madre degradada, que, al final de la historia, renace de las cenizas ${ }^{20}$.

Como en un juego de espejos infinitos, las dos Cenicientas del cuento de Perrault, la sirviente y la princesa, son una duplicación del mismo personaje, en tanto que Alina y Lejana son una duplicación de sí mismas y, a la vez, el desdoblamiento de Cenicienta. Sin embargo, como se verá a continuación, la historia de Alina invierte el signo de estos elementos: la mujer elige llevar una existencia entre cenizas y renuncia a la sexualidad. Veamos cómo se refleja, de manera invertida, una historia en la otra ${ }^{21}$.

20. Cfr. Bettelheim. 356-369.

21. En este cuento, como en otros de hadas. existen elementos cuya repetición da la idea de la multiplicidad. Cenicienta tiene dos madres. la biológica y la madrastra. quien a su vez tiene dos hijas. las hermanastras "que en todo se le parecian»: el padre se casa dos veces: Cenicienta es el doble de su madre «y en todo parecida a su madre». asiste dos veces al baile y el hada se aparece dos veces para darle un traje en cada ocasion: la boda se realiza doblemente, porque Cenicienta nace casar a sus hermanas el mismo dia. Charles Perrault, "La Cenicienta». en Titanes de la literatura intantil (México: Dıana. 1963). 
Los dos personajes presentan una realidad cotidiana con la cual no están satisfechas, ambas se mueven uniformemente, pues las dos realizan oficios domésticos. Cenicienta está al servicio de su madrastra y sus hermanas, con quienes mantiene cierta rivalidad, que se advierte únicamente en su interior: «Le mandó fregar los platos y el suelo, arreglar todas las habitaciones y los vestidos». «Este fue un nuevo trabajo para Cenicienta, tenía que preparar los trajes de sus hermanastras, planchar la ropa blanca y peinarlas y arreglarlas» ${ }^{22}$. Por su parte, Alina es una joven dedicada a las labores de la casa, las cuales realiza por compromiso o por complacer a su madre, con quien presenta una relación ambigua de rechazo y dependencia. Por un lado, la complace en todo momento: «corto un vestido o son las horas de recibo de mamá y yo sirvo el té» (91). Por otro, se expresa así en relación con su progenitora: «Me acosté con gusto a bombón de menta, al Boggie del Blanco Rojo, a mamá bostezada y cenicienta (como queda ella a la vuelta de las fiestas), cenicienta y durmiéndose, pescado enormísimo y tan no ella» (90). Y menciona, en algún momento, a «una madre furiosa» (93). La connotación negativa de la madre parte de la inconformidad que siente Alina, y que se representa en la bipartición madre-animal, alude a problemas sexuales ocultos. En este caso, el significado del pez asexualiza el nacimiento y simboliza el abandono del nacimiento ${ }^{23}$.

\section{Los zapatos de cristal}

Desde los orígenes, los zapatos constituyen un elemento central del cuento de Cenicienta. Como se dijo, fue Perrault quien cambió las chinelas originales propias de la tradición por zapatillas de cristal.

En ambos cuentos, el calzado es prueba de la identidad real. En el caso de Cenicienta, los zapatos de cristal, símbolo de riqueza y abolengo, pertenecen a la parte de Cenicienta que es princesa: «Así

22. «La Cenicienta». 103.

23. En los mitos y los cuentos de hadas, las relaciones familiares siempre son perturbadas y se relacionan con sentimientos de insatisfacción y rivalidad sexual. 
era, en efecto, pues, pocos días después, el hijo del rey hizo publicar a son de trompetas que estaba dispuesto a casarse con la mujer a quien le quedara bien el zapatito» ${ }^{24}$.

En el caso de Alina, los zapatos no son de cristal como los de Cenicienta, sino parte del vestuario de mendiga: «Ahora la nieve me entra por los zapatos rotos» (91). Están rotos y helados, pertenecen a su identidad de mendiga que es su otro yo, el que finalmente se impone: «Ahora sí gritó. De frío, porque la nieve le estaba entrando por los zapatos rotos» (98).

Los zapatos son, entonces, tanto elementos de duplicidad como parte del juego de opuestos, pues no son de cristal. Cenicienta reclama su reconocimiento como princesa y esposa del príncipe por medio de los zapatos de cristal, Alina se reconoce al fin como una mendiga por medio de los zapatos rotos que dejan pasar el frío.

\section{El vestido}

Cenicienta y Alina tienen vestidos diferentes que sirven para otorgarles su condición de realidad. En «Cenicienta», el cambio de vestido testimonia la asunción de una situación privilegiada, de los harapos cenicientos pasa a vestidos cortesanos primorosos. Los harapos la identifican como una mendiga en su vida cotidiana, lo maravilloso irrumpe y se convierte en una princesa, con nuevo vestido: «No hizo su madrina más que tocarla con la varita mágica y sus míseros harapos se convirtieron en preciosos vestidos de oro y plata, incrustados de piedras preciosas» ${ }^{25}$. El vestido reafirma el poder y consolida la personalidad: «Y en esto llegó el hada madrina que tocando con su varita mágica los andrajos de Cenicienta, los convirtió en un traje todavía más hermoso y rico que los dos que había llevado a los bailes del rey» ${ }^{26}$. 
Lo anterior se relaciona con un rasgo de los cuentos de hadas y los mitos, en los que contrastan los vestidos de las reinas y los reyes con los de los mendigos, para reafirmar la diferencia entre ellos.

Enun sentido inverso, en el desdoblamiento de Alina quien lleva el mejor vestido es la princesa del anagrama, es decir, Lejana - la otra Alina: «Iba Alina Reyes lindísima en su sastre gris» (98). Así, la degradación de Alina se subraya con su vestimenta, otro elemento de duplicación y reconocimiento.

El color del vestido es un símbolo de bienestar y autenticidad, en el caso de Cenicienta pasa de ser «ceniciento», es decir, «gris» a ser de oro, plata y piedras preciosas. En «Lejana», el vestido de Alina Reyes que era un «sastre azul», en el momento de la fusión es «un sastre gris», o sea, ceniciento. Es importante anotar que el gris simboliza pobreza y malestar físico, mientras que el azul significa espiritualidad.

\section{El baile}

El baile es otro elemento retórico de duplicidad. Para Cenicienta forma parte de lo fantástico y lo maravilloso, pues se escapa de su rutina. En la realidad Cenicienta se dedica a oficios domésticos y no a los placeres de la corte: «¡Ay por Dios! ¿Por qué os reís de mí? ¡El baile del rey no es sitio adecuado para una pobre como yo!» ${ }^{27}$

A pesar de su queja, asiste a dos bailes, ambos ligados lógicamente a la presencia masculina, la cual constituye la recompensa de la joven. El baile forma parte del parecer-querer de Cenicienta, quien intenta transformarse por medio de las fiestas cortesanas, la ropa y los zapatos con la intención de lograr su boda con el príncipe ${ }^{28}$.

Alina, por el contrario, es una joven moderna, le gusta ir a fiestas, bailes y conciertos que son parte de su vida cotidiana, de su rutina: «Luis María baila conmigo» (91).

27. "La Cenicienta». 104.

28. Joseph Courtes. "Une lecture sémiotique de Cendrillon». en Introduction a la vémiologique' narrative et discursire. methodologie et aplication (París: Hacchette. 1976) 109-137. 
También será en el espacio del baile donde ocurran los encuentros de Alina con lo fantástico, ya que empieza a percibir la soledad y la pobreza de Lejana mientras baila con su novio: «cuando conozco sobre ella y justo estoy bailando con Luis María» (92).

\section{El príncipe}

Cenicienta encuentra un príncipe, la pareja se conoce en el baile; el personaje masculino será el medio para que Cenicienta alcance su transformación: «El hijo del rey la hizo sentar en el puesto de honor y enseguida le pidió que le concediera el honor de bailar con ella» ${ }^{29}$.

Por el contrario, quien ayuda a Alina es un «peón», un subordinado, en el juego de ajedre $z^{30}$ que representa el Diario de Alina, y en el cual una reina desplaza a otra: «Me pareció que él entraba fácilmente en ese juego» (96). «Luis María, al lado de su reina» (96). «Es como un peoncito de dama que retoma la partida sin sospecharlo» (96).

\section{La boda}

De alguna manera, la boda permite un desdoblamiento porque los personajes se convierten en otra persona: Cenicienta se transforma en princesa y Alina en mendiga.

Hay, sin embargo, importantes diferencias. Al final del cuento, Cenicienta contrae matrimonio, de esta manera adquiere poder y reconocimiento social, autentica su verdadera categoría de princesa, se da un cambio positivo. Es una joven bella aun en sus harapos, que externa su bondad y su belleza reales por medio del matrimonio: «Así vestida, la condujeron los pajes del rey a donde el príncipe la esperaba. Al príncipe le pareció más bella que nunca y pocos días después se celebraron sus bodas» ${ }^{31}$. Alina, por el contrario, en su afán de buscar a la Lejana, se casa con «un peón».

29. «La Cenicienta». 100.

30. Alina es la reina blanca. Lejana. la negra. Ambas se mueven desde extremos opuestos del tablero (día-noche) hacia el centro de este. (que corresponde al día 24 de enero. Una reina será desplazada: «y será la victoria de la reina sobre esa adherencia maligna» (97). Hay incluso un rey. aunque prisionero: "La cadena cue Rex arrastra toda la noche contra los ligustros» (90).

31. "La Cenicienta». 108. 
En ambas historias, el amor no constituye un enlace con la pareja, más bien está sustituido por intereses personales. A Cenicienta la mueve el afán de cambiar su yo. El matrimonio es un medio, su realización logra un único objetivo. Para Courtes «el cuento es una historia de un matrimonio», sin embargo, la decisión de la boda no procede del príncipe, sino que es provocada por Cenicienta ${ }^{32}$. A Alina la mueve el deseo de encontrar su otro yo en una mendiga: «Decirle a Luis María: Casémonos y me llevas a Budapest a un puente donde hay nieve y alguien» (93), participa del matrimonio únicamente como un obstáculo que debe vencer para llegar a Lejana. Una vez obtenido su objetivo de imponerse a la parte luminosa de la mujer, la otra Alina, la. Lejana, se divorcia.

En los cuentos de hadas, la pareja sexual se representa bajo la forma de un animal (animal-novio), debido al tabú sexual. Una situación semejante sucede con Alina: «Ahora estará mi cachorro. Mi bobo, basta de pensar y a ser al fin y para bien» (97).

El personaje masculino solamente se humaniza si logra el amor de la mujer. En el caso de Luis María no se completa el proceso de humanización, por cuanto una vez alcanzado el fin, se prescinde del personaje masculino: «Eso era dos meses antes de su divorcio» (97). El matrimonio no es realización de la pareja, sino el eslabón básico para encontrar al doble, lograr este encuentro con el Otro, la realización y objetivo primero de todo esfuerzo. La personalidad fragmentada tiene dificultades para crear lazos afectivos, pues su único objeto es la lucha por la supremacía entre el yo y el otro, razón por la cual no existe expresión de lo sexual como complemento de la relación de pareja. Como explica Freud, el desdoblamiento es provocado por «un conflicto entre las aspiraciones de la sexualidad y las del yo que no permite mantener la relación afectuosa» ${ }^{33}$.

32. Joseph Courtes, 137.

33. Sigmund Freud. El malestar de la cultura (traducción de Ramón Pérez Ardid y Luis López Ballesteros. Madrid: Alianza, 1994) 139. 
En los dos cuentos el desdoblamiento se logra por la repetición de elementos retóricos que dan la idea de multiplicidad. Ambos personajes deben atravesar un largo camino y vencer una serie de obstáculos para alcanzar sus objetivos relacionados con el encuentro, su yo verdadero o el Otro que debe aceptarse e integrarse. Sin embargo, en el caso de Alina, incapaz de asumir su sexualidad y de superar una relación conflictiva con su madre, se impone la personalidad oscura de la Lejana, la que la tortura en sueños: el viaje de Alina repite de manera inversa el periplo de Cenicienta.

En resumen, Alina y Cenicienta son los opuestos a sí mismas. Cenicienta se transformará en una Alina cuando se case, mientras que Alina se convertirá en una Cenicienta cuando se encuentre con Lejana: Lejana, vestida de harapos, maltratada, hambrienta y solitaria es la sirvienta del cuento y Alina, espléndida, amada, feliz y acompañada es la princesa. Así el mito se revela como el trasfondo del cuento. 